\title{
Multiple re-entry gunshot wounds possibly inflicted by a single shot: Case report
}

Received: 19 October, 2020

Accepted: 28 December, 2020

Published: 29 December, 2020

*Corresponding author: İsmail Özgür Can, MD, Department of Forensic Medicine, Faculty of Medicine, University in İzmir, Turkey,

E-mail: ozgur.can@deu.edu.tr

https://www.peertechz.com

Check for updates

\section{Çağdaş Savaş ${ }^{1}$ Emir Derkuş ${ }^{1}$, Umut Erdar Bilgin² and İsmail Özgür Can ${ }^{1 *}$}

${ }^{1} \mathrm{MD}$, Department of Forensic Medicine, Faculty of Medicine, University in İzmir, Turkey

${ }^{2} \mathrm{MD}$, İzmir Forensic Medicine Institution Group Presidency, Turkey

Fireguns continue to attract people's attention today as they have in the past. People obtain fireguns for individual purposes such as hunting, protection or defense. Again, firearms are manufactured for institutional purposes and used for deterrence, defense, and even for attacking in order to eliminate danger and threat [1].

Firearm wounds are frequently encountered in forensic practice [1]. The person can shoot himself or be shot by someone else. Firearm wounds have the same appearance in either case. Therefore, autopsy is recommended for firearmrelated deaths [2].

Firearm wounds are examined by forensic medical experts for the identification of ballistic trajectory as well as entry and exit wounds. In case of firegun-related injuries, it is important to make investigations to determine the shooting distance, to determine the entry and exit wounds, to analyze the residues on the clothes and the body, and to preserve the clothes $[1,2]$.

These investigations reveal the shooting direction, shooting distance, weapon type, victim position at the time of shooting, direction of the bullet hitting the body and the relevant organs. However, it is difficult to determine the shooting distance and to distinguish the entry-exit wounds in patients who have unknown injuries, no initial examination findings and received medical treatment $[2,3]$.

Another difficulty encountered in distinguishing entry and exit wounds is when there are re-entry wounds. It is quite common for different parts of the body to be injured by one projectile because a single firearm projectile can cause several injuries. Re-entry wounds occur when a projectile pierces one part of the body such as an arm and then enters another part of the body such as the rib cage, for example. The most common situation is when the bullet travels across the arm or leg and then re-enters the abdomen or chest. Initially pierced body parts such as arms or legs, can be considered as an intermediate target. Placing the limb in the proper position immediately clarifies the situation and can significantly aid direction estimation $[4,5]$.

Determining the number of shots in firearm injuries is important in cases in order to determine the origin by judicial authorities where there is more than one suspect. Consequently, re- entry wounds should be taken into consideration when interpreting the number of shots. In cases with re-entry-exit wounds, trajectory can be detected in the examination where the limbs such as arms and legs are placed in the appropriate position at autopsy.

In this case, the same bullet entered from the posterior left shoulder and exited from the left side of the neck and then reentered $2 \mathrm{~cm}$ above the area where it exited on the neck, causing injury to re-exit from the back of the right ear, resulting in reentry-exit wounds in this manner. It has been determined that there are differences between re-entry-exit wounds, which are widely seen in the literature, in terms of factors such as injury site and trajectory, therefore, our report aimed to discuss the methods to be followed to determine the number of shots, trajectory and entry-exit wounds in autopsies performed in re-entry-exit injuries, and to emphasize that re-entry and exit wounds should be taken into account in single-shot cases where it is difficult to distinguish entry-exit wounds. 


\section{Case}

\section{External examination}

It was observed that the body underwent an abdominal operation, primary colon repair surgery in the hospital where the victim was admitted due to multiple firearm injuries. He was a 33-year-old male, $185 \mathrm{~cm}$ tall, of normal build, and weighing $92 \mathrm{~kg}$. The postmortem rigidity was observable in all joints, and postmortem lividity appeared in purple on the back, lumbar region and gluteal region where there was no pressure, and faded with pressing. There were no signs of decay.

On the body, there was a yellow-black and red-colored tiger figure tattooing on the left side of the chest on the front of the body in a $17 \times 13.5 \mathrm{~cm}$ area, a blue-black orange-red female warrior figure in a $24 \times 20 \mathrm{~cm}$ area starting from the left shoulder and extending to the left arm, and black, red and green female skeleton, compass and clock figures in a $34 \times 20$ $\mathrm{cm}$ area starting from the right shoulder to the elbow.

All wounds with surgical suture material were opened and the existing gunshot wounds were enumerated:

1) A $1 \times 0.9 \mathrm{~cm}$ firearm entry wound at the posterior left shoulder with an inferolateral $0.3 \mathrm{~cm}$ crescent-shaped pink ecchymosis and scratch.

2) A $1 \mathrm{~cm}$ firearm exit wound with $0.5 \mathrm{~cm}$ abrasion on the front upper half, with a $13 \times 6.5 \mathrm{~cm}$ red-purple ecchymosis extending to the left shoulder on the left side of the neck.

3) A $0.7 \mathrm{~cm}$ firearm entry wound with an $0.3 \mathrm{~cm}$ ecchymosed scratch on the anterior upper half, just above the lesion number 2 in the area described above.

4) A $1 \times 0.7 \mathrm{~cm}$ firearm exit wound with a $7 \times 6 \mathrm{~cm}$ purple ecchymosis behind the right ear.

5) A $0.5 \mathrm{~cm}$ firearm entry wound in the lumbar region of the waist at the level of the T12-L1 vertebra on the right paravertebral line, with a $0.3 \mathrm{~cm}$ contusion ring.

6) A $7 \times 3.5 \mathrm{~cm}$ firearm exit wound with irregular edges, with $2 \times 0.4 \mathrm{~cm}$ purple ecchymosis on the upper right quadrant of the abdomen.

7) A $0.6 \times 0.4 \mathrm{~cm}$ firearm entry wound in the medial of the right knee, with a metallic body inside.

On the body, a $23 \mathrm{~cm}$ long vertical incision was observed starting from the midline xiphoid of the abdomen and crossing the umbilicus with metal suture material around the $23 \times 6$ $\mathrm{cm}$ area with ecchymosis in pale brown green purple mottled appearance. A $0.5 \times 0.3 \mathrm{~cm}$ sutured drain wound was observed in the right lower quadrant of the abdomen while a $1.5 \times 0.3 \mathrm{~cm}$ sutured drain wound was observed in the left lower quadrant of the anterior abdomen. Injection marks were observed on the upper $1 / 3$ anterior of both forearms, dorsum of both hands and in the antecubital region.
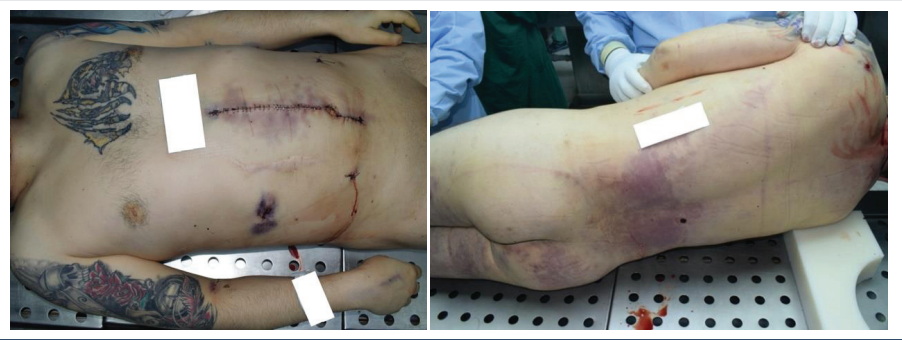

General view of the body from the anterior and posterior.

No other traumatic findings were detected except for the gunshot wounds described. The fluoroscopy examination revealed a millimetric metallic body in the medial of the right knee, and a fracture in the left scapula.
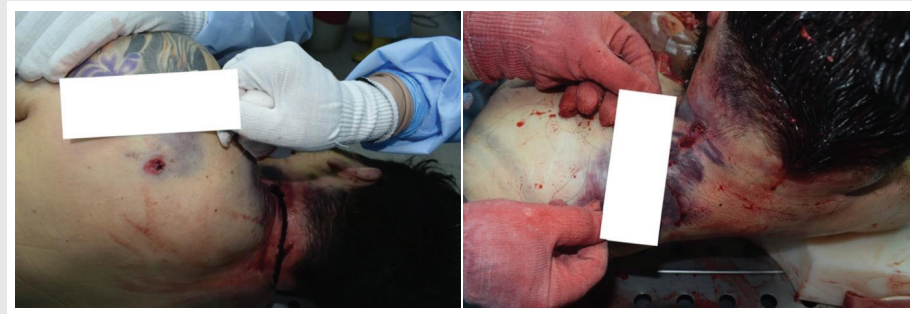

Gunshot wound numbered 1 posterior to the left shoulder

Gunshot wounds numbered 2 and 3 on the left of the neck.
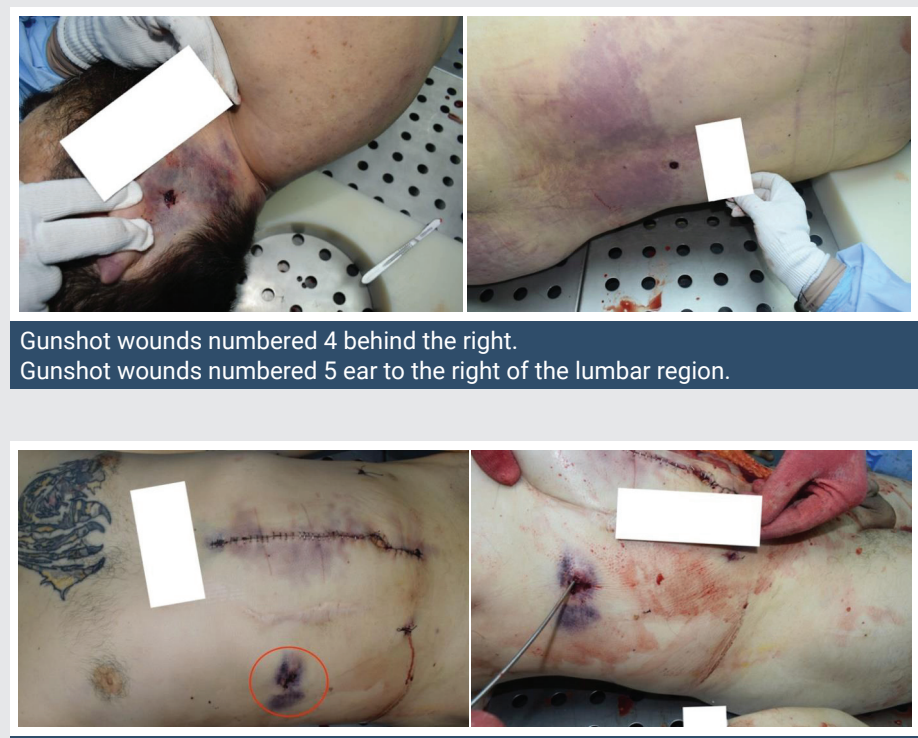

Gunshot wound numbered 6 in the upper right quadrant of the abdomen.

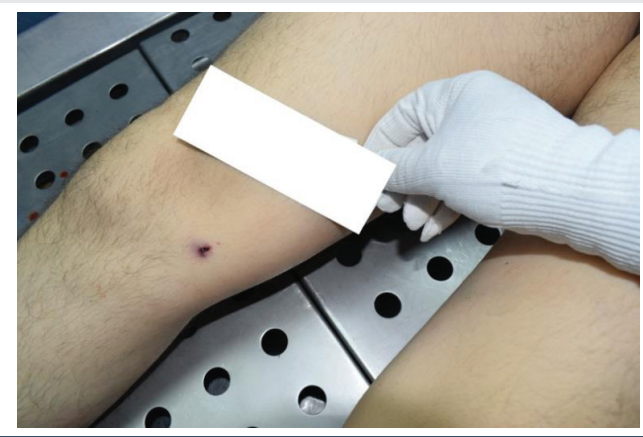

Gunshot wound numbered 7 in the medial of the right knee. 


\section{Internal examination}

When the skull was opened and the dura mater was removed, we observed a subdural hemorrhage of $6 \times 2 \mathrm{~cm}$ in the right frontal lobe and $9 \times 2 \mathrm{~cm}$ in the side facing the interhemispheric area in the parietal lobe, and a diffuse subarachnoid hemorrhage in both parietooccipital lobes. The brain, cerebellum and organs that make up the brainstem were removed and weighed 1314 grams. Subdural hemorrhage in the brain stem and diffuse areas of contusion in both cerebellum lobes were observed. A $3 \times 2.2 \mathrm{~cm}$ bleeding site was observed around the circle of Willis. The examination of neck organs revealed bleeding in the cervical vertebrae at a $10 \times 5 \mathrm{~cm}$ area in the soft tissues on the left and in the dura at $\mathrm{C} 1$ level in the medulla spinalis. Both carotid arteries and jugular veins were intact. No macroscopic pathological features were observed in the examination of the chest organs. Soft tissue bleeding was observed under the left clavicle. Both subclavian arteries and veins were intact. No macroscopic pathological features were observed in the examination of the heart. Widespread bleeding was observed in subcutaneous and soft tissues on the right side of the abdomen. $100 \mathrm{cc}$ of blood was detected in the abdominal cavity. The liver was attached to the diaphragm and removed, weighing $1349 \mathrm{~g}$. A $6 \times 1 \mathrm{~cm}$ contused area was observed on the liver to the diaphragm. Kidneys were removed; left kidney weighed 129 gr and right kidney weighed 121 gr. Organized hematoma of $15 \times 12 \mathrm{~cm}$ was observed in the right kidney cavity and a laceration of $5 \times 4 \times 1 \mathrm{~cm}$ was observed under the right kidney with loss of cortex. No macroscopic pathological features were observed in the pancreas and small intestines. There was a laceration of $20 \times 10 \mathrm{~cm}$ in the ascending colon meso, diffuse ecchymosis under the meso, and a $5 \mathrm{~cm}$ sutured perforated area in the ascending column. Both iliac arteries and veins were intact. Bone structures and soft tissues of the pelvis were examined and no macroscopic pathological features were observed. An incision was made medial to the right knee and a metallic body was removed under the skin.

\section{Trajectory analysis of the gunshot wound pathways was as follows}

It was detected that the metallic body entering the wound location identified in No. 1 (left shoulder posterior) in external examination, assuming that the body was in the anatomical location, exited the body through the wound location in No. 2 (left shoulder posterior) after proceeding from left to right, from bottom to top, causing a fracture of the scapula.

The metallic body of the gunshot injury entering the wound location identified in no.3 (left of the neck) in external examination, exited the body through the wound location identified in 4 (back of the right ear) after proceeding from left to right, from bottom to top, causing hemorrhage on the dura in the medulla spinalis, subdural hemorrhage, contusion and subarachnoid hemorrhage in the brainstem, cerebellum and brain without causing a fracture in the cervical spine and skull.

It was also detected that the injury caused by the metallic body entering from No. 3 and exiting No. 4 may be a continuation of the injury caused by the metallic body of the firearm entering from No. 1 and exiting No. 2.

It was detected that the metallic body entering the wound location identified in No. 5 (in the right lumbar region of the waist) in external examination, assuming that the body was in the anatomical location, exited the body through the wound location in No. 6 (right abdomen) causing injury (laceration, bleeding, contusion and perforation) in the ascending colon and meso, right kidney and liver after proceeding from posterior to anterior, from bottom to top, and from slightly left to right.

The metallic body of the firearm entering the body from the injury site identified in No. 7 (medial to the right knee) in external examination remained in the subcutaneous tissue and did not cause large vessel or nerve damage.

In conclusion, there were 4 (four) firearm entry wounds on the body and each of the injuries caused by the shots that constitute the wound identified as lesion 3 and 5 in the external examination was of fatal nature. On the other hand, the injuries caused by the shot that constitutes the entry wound identified as lesion 1 and 7 in the external examination were not fatal, and the injury caused by the metallic body of the firearm entering from No. 3 might be the continuation of the injury caused by the metallic body of the firearm entering from No. 1 . According to the findings of external and internal examination, it was deemed necessary to determine the exact firing distance by analyzing residue on the unwashed clothing worn by the person at the time of the incident and which contained a firearm entry hole since the shots that constitute the firearm wound identified in No. 1, 5 and 7 targeted the clothed area, and the shot that constitutes the firearm wound identified in No. 3 may be a continuation of the shot identified in No. 1. It was also determined that death occurred due to gunshot wounds as a result of internal organ injury (contusion, laceration and perforation of the liver, right kidney, ascending colon and meso) and internal bleeding (hemoperitoneum) between the cerebrospinal stem and spinal membranes (subarachnoid, subdural, epidural and intraparenchymal hemorrhage).

\section{Discussion and conclusion}

In firearm injuries, it is of great importance to determine the direction and level of the fire, determine the number of shots, what kind of weapon the injury was caused by, and the shooting distance and entry-exit wounds in terms of making an accurate judgment in the judicial process, especially in case of more than one suspect or with regard to the manner and origin of the incident. The relationship between the ballistic trajectory, localization of the wound and the distance between the gun barrel and the target should be evaluated to determine whether the incident was homicide or suicide. Because the occurrence of the event as a result of murder, accident or suicide brings about different criminal convictions. In addition, the finding of elongation in entrance wounds is also important. The detection of entry and exit wounds and the determination of the shooting direction are stated to be significant indicators in the evaluation of whether the incident was suicide or homicide [3].

Citation: Savaş Ç, Derkuş E, Bilgin UE, Can IÖ (2020) Multiple re-entry gunshot wounds possibly inflicted by a single shot: Case report. Forensic Sci Today 6(1): 026 
It may be difficult to determine the number of shots and the shooting distance, and to distinguish between entry-exit wounds in cases with multiple entry-exit wounds,it is not known how the injury occurred, there are no first examination findings, and especially those who have received medical treatment [3].

In a case presented in the literature on this subject, the body of a 73-year-old male was found in a truck where external examination found 18 gunshot wounds on the upper arms, neck and head, but 6 shots were fired according to the police report, revealing a case of re-entry and exit wounds [6]. In another case, it was determined that the victim had 2 entry and one exit wounds due to a firearm injury, where it was later found that the victim was leaning against the wall when shot, and the bullet came out of the victim's back and bounced off the wall and entered the body again [5].

In our case, there was difficulty in distinguishing and tracing firearm entry-exit wounds due to factors such as the presence of surgical wounds on the victim's body as a result of medical intervention in the hospital where he was admitted after being shot, loss of the characteristics of some described firearm wounds after surgical intervention, and inadequate information in forensic analysis. In addition, the forensic investigation file did not contain information about the ballistic examination. For this reason, a definite assessment could not be made regarding the ammunition and weapon type used.

Gunshot wounds typically appear as central tissue defects with a thin circular blackish abrasion rim resulting from the accumulation of lubricant, dirt and rust in the barrel on the tissue during penetration by the projectile, an abrasion ring around the abrasion rim and ecchymotic area at the outermost part. However, not all of these are always seen. Most entry wounds appear as circular punctures with an abrasion margin or abrasion ring. Abrasion margin is produced due to stretching as the bullet enters the body by ultimately tearing the adjacent skin surface and is the most reliable feature in identifying entry wounds. Abrasion margin can provide useful preliminary information regarding the trajectory of a projectile within the body. Abrasion margin is symmetrical when the bullet enters the body perpendicularly. When the bullet enters the body at a certain angle, the margin on the side where the bullet first contacts the skin will increase $[4,7]$.

The wound morphology that occurs in firearm exit wounds is variable, they are generally larger and irregular than the entry hole. Exit wounds are generally in the form of an irregularly shaped lesion in which the skin and tissues are torn outward. In contrast to the entry, the skin at the exit protrudes outward and generally appears as slit-like or irregular holes with no wear margins $[4,7,8]$.

Injury at two parts of the body with a single shot is quite common. Re-entry wounds occur when a bullet pierces one part of the body, such as an arm, and then enters another area, such as the chest. Initially pierced body part can be considered as an intermediate target. Re-entry wounds commonly present as a large and irregular defect with ragged edges and a wide abrasion ring but no bullet wipe-off $[4,5]$.
In our case, gunshot injuries defined in the waist, abdomen and right knee medial were tracked as initially thought. Considering the position of the body during the shooting it would have been possible to consider the possibility that the wound number 7 is a re-entry wound from number 6 , but the data that is given by the crime scene investigation officers did not reveal the position of the body or present any video recordings of the shooting. Therefore during the autopsy and the preparation of the autopsy report, we didn't consider the possibility that the wound number 7 would be a re-entry wound from the wound number 6 .

Detailed examination in the later stages of the autopsy revealed an entry wound (Figure 1) with an angled, bottom-up trajectory due to its oval shape and the downward extension of the abrasion ring, considering the morphological features of the gunshot wound at the posterior of the left shoulder (node 1). The gunshot wound identified in No.2 on the left of the neck was considered as an exit wound because it was large, irregularly shaped and did not contain an abrasion ring. The gunshot wound defined in No.3, did not have typical features such as circular shape, bullet wipe and ecchymotic area in the entrance wounds However, considering the abrasion area with dermal-epidermal loss just before it, it was evaluated as an atypically shaped entry wound. Due to the abrasion area with epidermal-dermal loss between gunshot wounds identified on the left side of the neck (nodes 2 and 3) adjacent to both wounds, these two wounds were thought to be a continuation of each other throughout the pathway of the projectile, and as a result, the metallic body of the firearm entering the body from the left shoulder posterior (node 1) left the body from the area defined in No.2 on the left of the neck. Again, it was thought that the lesion identified in No. 2 on the left of the neck, reentered $2 \mathrm{~cm}$ above (No. 3) and left the body behind the right ear (No. 4) (Figures 2,3).

In conclusion, we are of the opinion that the evaluation should be made in accordance with the forensic analysis and medical treatment documents in cases where it is difficult to distinguish between firearm entry-exit wounds, it is not known how the injury occurred and the initial examination findings are unavailable.We believe that it should also be taken into account that multiple firearm entry and exit wounds may occur with a single shot.

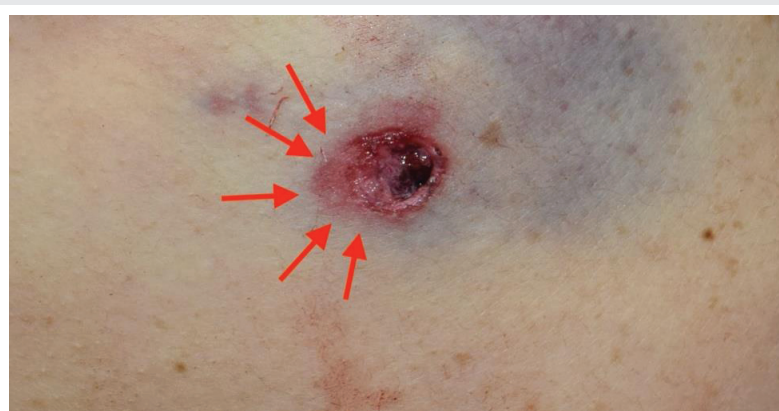

Figure 1: Gunshot wound identified at number 1 posterior to the left shoulderabrasion ring indicated by red arrows-according to anatomical position; an angled entrance from the bottom to the top.

Citation: Savaş Ç, Derkuş E, Bilgin UE, Can IÖ (2020) Multiple re-entry gunshot wounds possibly inflicted by a single shot: Case report. Forensic Sci Today 6(1): 026 


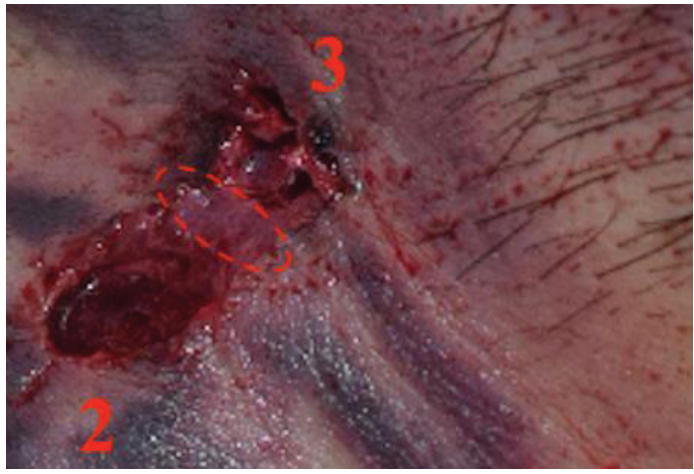

Figure 2: Dermal-epidermal loss shown between number 2 and 3 gunshot wounds identified on the left of the neck-Gunshot wound that came out from number 2 and re-entered the body at number 3 .

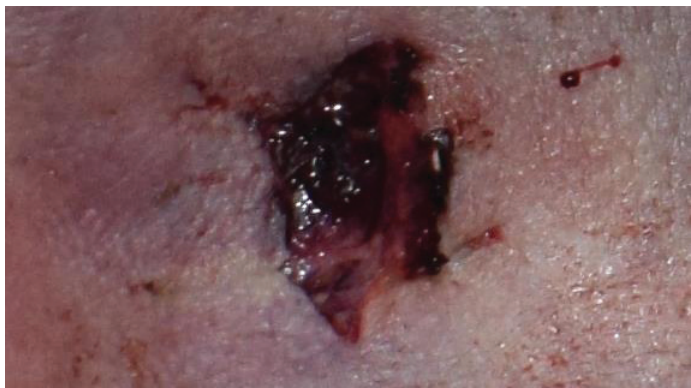

Figure 3: Gunshot wounds numbered 4 behind the right ear- close-up photo.

\section{References}

1. Kafadar H, Kafadar S (2017) Yaşamsal tehlike oluşturan atipik seyirli ateşl silah yaralanması. olgu sunumu. Adıyaman Üniversitesi Sağlık Bilimleri Dergisi 3: 453-459. Link: https://bit.ly/2MgA4SE

2. Color Atlas of the Autopsy (2017) Chapter 4 External Examınatıon: Forensıc Injurıes, Firearms, Second Edition. Link: https://bit.ly/3nYYPRb

3. Çelikel A, Cengiz ARLI, Zeren C, Demirkiran DS (2013) Maksillofasiyal ateşli silah yaralanmalarında atış yönünün belirlenmesinde radyografık görüntülemenin önemi. Dicle Tıp Dergisi 40: 432-435. Link: https://bit.ly/3hqDPQR

4. Handbook of Forencic Medicine (2014) Edited by Burkhard Madea Forensic Ballistics: Injuries from Gunshots, Explosives and Arrows. Link: https://bit.ly/38IWC5Z

5. Knıght's Forencic Pathology (2016) Pekka Saukko/Bernard Knight, Chapter 8: Gunshot and Explosion Deaths, Fourth Edition. Link: https://bit.ly/3rBIsMQ

6. Maiese A, Gitto L, De Matteis A, Panebianco V, Bolino G (2014) Post mortem computed tomography: useful or unnecessary in gunshot wounds deaths? Two case reports. Leg Med 16: 357-363. Link: https://bit.ly/3aRaLB0

7. Color Atlas of Forensic Medicine and Pathology, Chapter 8 Gunshot Wounds, Second Edition 2016. Link: https://bit.ly/3nVh1Lu

8. Şimşek Ü (2017) Eskişehir ilinde 2009-2015 yılları arasında ateşli silah yaralanmasına bağı ölüm olgularının değerlendirilmesi. Link: https://bit. ly/3mWbNhd
Discover a bigger Impact and Visibility of your article publication with

Peertechz Publications

\section{Highlights}

* Signatory publisher of ORCID

* Signatory Publisher of DORA (San Francisco Declaration on Research Assessment)

- Articles archived in worlds' renowned service providers such as Portico, CNKI, AGRIS, TDNet, Base (Bielefeld University Library), CrossRef, Scilit, J-Gate etc.

* Journals indexed in ICMJE, SHERPA/ROMEO, Google Scholar etc.

* OAI-PMH (Open Archives Initiative Protocol for Metadata Harvesting)

* Dedicated Editorial Board for every journal

* Accurate and rapid peer-review process

* Increased citations of published articles through promotions

- Reduced timeline for article publication

Submit your articles and experience a new surge in publication services (https://www.peertechz.com/submission).

Peertechz journals wishes everlasting success in your every endeavours.

Copyright: ๑ 2020 Savaş Ç, et al. This is an open-access article distributed under the terms of the Creative Commons Attribution License, which permits unrestricted use, distribution, and reproduction in any medium, provided the original author and source are credited. 